\title{
erratum
}

\section{Arrangement of subunits and ordering of $\beta$-strands in an amyloid sheet}

Ahmed A. Serag, Christian Altenbach, Mari Gingery, Wayne L. Hubbell and Todd O. Yeates

Nat. Struct. Biol. 9, 734-739 (2002).

Because of a mistake that occurred during production of this manuscript, the wrong panel was printed in Fig. $2 c$. The correct panel is now reproduced. We apologize for any inconvenience this may have caused.

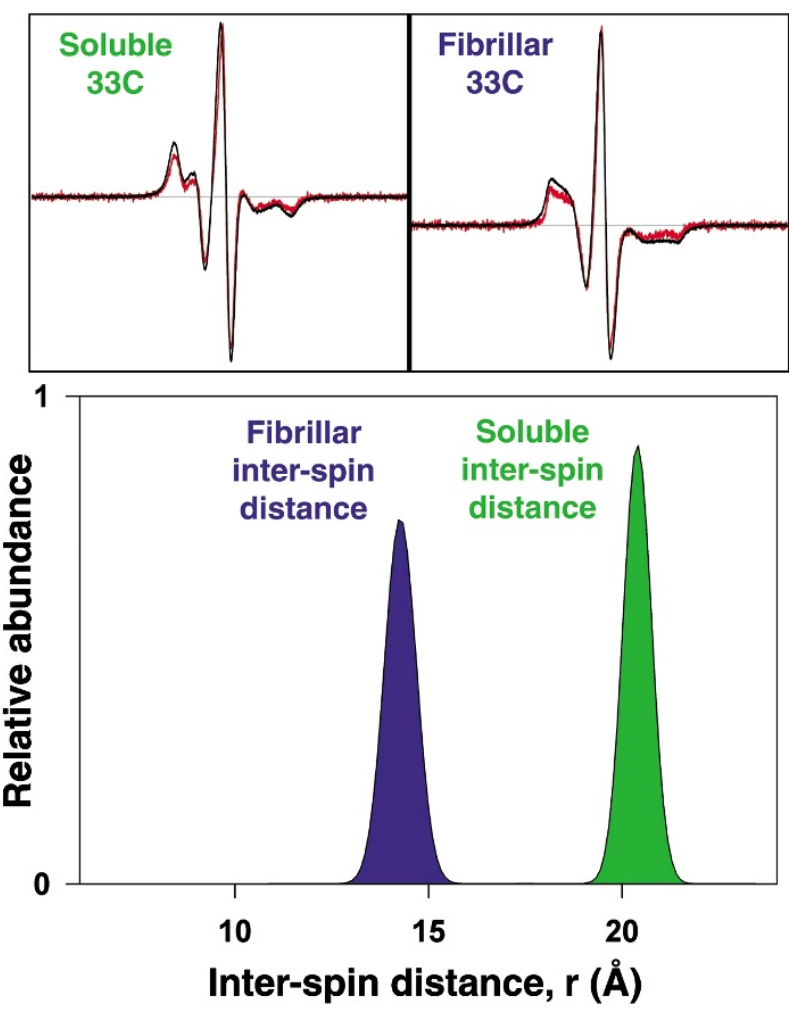

